\title{
Understanding the changing role of global public health in biodiversity conservation
}

\author{
Will Smith
}

Received: 17 March 2021/Revised: 6 May 2021/Accepted: 16 May 2021 / Published online: 11 June 2021

\begin{abstract}
Zoonotic disease emergence has become a core concern of biodiversity conservation amid the ongoing impacts of the COVID-19 pandemic. Major international conservation groups now comprehensively center larger human-nature imbalances not only as problems of global public health but as a core challenge of the conservation movement, alongside habitat destruction, biodiversity loss and climate change. There is, however, little consideration of how new biosecurity concerns might alter conservation practice with unexpected and potential harmful impacts on human communities, particularly in developing nations with significant human-wildlife interfaces. Reviewing emerging policy positions from key conservation organizations, this article argues that the proposed responses to the COVID-19 pandemic hold the potential to (a) amplify existing people-park conflicts, and (b) generate new tensions by integrating global systems of viral surveillance into biodiversity conservation. I conclude that the close integration of biosecurity concerns into conservation policies requires greater acknowledgment of the unique challenges for human communities.
\end{abstract}

Keywords Biosecurity · Biosurveillance · COVID-19 . One health $\cdot$ Zoonosis

Supplementary Information The online version of this article (https://doi.org/10.1007/s13280-021-01576-0) contains supplementary material, which is available to authorized users.

\section{INTRODUCTION}

The relationship between global public health and conservation has changed dramatically over the course of 2020 and 2021. In large part, the growing convergence of these two concerns has emerged from the proposed origin of SARSCov-2 and the resulting COVID-19 pandemic in wildlife sold in the wet markets of Wuhan. This scrutiny has focused on bats and pangolins, both known reservoirs of coronaviruses, and has alerted global publics to the extensive and illegal international trade in endangered animals as a site of potential "viral spillover" to humans. However, beyond a specific focus on the role of the illegal wildlife trade, scientists, media commentators and environmental activists have been quick to suggest that blame for the emergence of zoonotic diseases lies not just in wildlife trading but in environmental destruction more broadly. This includes changing climate, deforestation and intensification of agriculture and livestock production (Schmeller et al. 2020; Wu 2021).

In response to the growing awareness of the relationship between environmental and human health, "biosecurity"broadly, the management of harmful organisms-has become a pervasive feature of global conservation discourse, occupying an equal role alongside existential challenges of habitat destruction and climate change. In a striking example of this trend, the Wildlife Conservation Society, a longtime advocate for linking environmental and human health, elevated zoonotic diseases to a central conservation crisis in a statement to the new United States administration following the inauguration of President Joe Biden in January of 2021. The statement emphasized that "the United States needs to reengage in advancing environmental and conservation solutions as the world faces existential crises all caused by humankind: the loss of biodiversity, climate change, and the threat of pandemic 
disease". This is not an isolated perspective. Global public health is now a central, rather than peripheral, problem of biodiversity conservation. ${ }^{1}$

As this article demonstrates, there is an emerging and powerful consensus among scholars and practitioners that preventing future pandemics will require expansive and transformed environmental safeguards and a close integration of biodiversity conservation and global public health strategies. The language of conservation groups, in particular, has changed comprehensively over the course of 2020 and 2021 in response to heightened public awareness of zoonoses and intense governmental concern surrounding future viral pandemics linked to environmental change. This article is based on a review of the statements, policy briefings and reports produced by globally or regionally significant terrestrial conservation organizations that are concerned with the illegal wildlife trade, wildlife conservation or biodiversity conservation more broadly. Surveying these emerging responses demonstrates that the global conservation movement has quickly and collectively capitalized on public concern surrounding zoonotic diseases, and adopted positions that explicitly link the environment and zoonoses, resulting in what has been described by leading environmentalists as a "remarkable consensus among conservation groups about the future of the planet" (Conservation International 2020).

However, while COVID-19 has prompted considerable discussion around the future of conservation practice-in terms of economic viability and the ability to sustain ecosystems in the context of diminished enforcement (McElwee et al. 2020; Roe et al. 2020; Cawthorn et al. 2021) - there has been little consideration of how "biosecurity" concerns might distinctly alter the work of environmental protection and with what implications for communities who co-mingle with wildlife. The article identifies two emergent challenges. First, the potential emergence of zoonotic diseases has been used to draw attention toward existing mechanisms of environmental protection, specifically protected area expansion and more punitive action toward actors in the wildlife trade. This amplification may promote harsh and restrictive approaches to protected area management and further stigmatize the often-complex wildlife use of poor, rural peoples. This is a scenario borne out by tentative government responses, particularly in Southeast Asia, that include blanket bans on non-timber forest product trading and the more punitive measures targeting wildlife traders as solutions to zoonoses. Secondly, concern surrounding zoonosis has led to widespread calls from scholars and conservation

\footnotetext{
$\overline{1}$ The IUCN has produced a compilation of responses by multilateral organizations and high-profile political leaders and activists: https:// www.iucn.org/news/protected-areas/202102/natures-future-ourfuture-world-speaks.
}

practitioners to integrate viral surveillance into protected area design as part of a global system of pathogen monitoring. In addition to passive symptom monitoring of humans who reside at the human-wildlife interface, this has included a widespread renewal of longstanding calls for routine genetic sampling of humans and animals for emerging diseases at sites deemed to be at high-risk of viral spillover. However, these techniques may raise new tensions in an already fraught governance space, often marred by low levels of trust and historical, ongoing in certain areas, animosity surrounding conservation measures.

The high human and environmental costs of COVID-19 have provided a clear and compelling justification for these measures in the name of future pandemic prevention. The enthusiastic and widespread integration of human biosecurity concerns into environmental protection warrants careful investigation, and close regulation, to avoid deepening existing conflicts between communities and conservation goals.

\section{HOW HAVE BIOSECURITY CONCERNS ENTERED INTO CONSERVATION PRACTICE?}

Biosecurity is, to varying degrees around the world, an existing feature of environmental governance concerned with the management of animal and plant diseases. Most prominently, "One Health" approaches emerging in the early 2000s have been jointly adopted as a guiding concept with varying levels of application by multilateral groups (e.g., the World Health Organization, World Organization for Animal Health and the Food and Agriculture Organization). One Health, a concept rooted in understanding links between environmental and human health, has led to several significant national and international projects of viral surveillance and management (e.g., USAID PREDICT, the EU-funded ANTIGONE). However, until recently One Health and related approaches had not garnered significant public recognition or policy traction strictly as an issue of conservation. While nominally "cross-sectoral", the majority of existing One Health research activities and projects focus on preserving the economic viability of commercial intensive agriculture or livestock production (Hinchliffe 2015; Porter 2019), with little integration of traditional biodiversity conservation concerns, such as habitat preservation or protected area management. ${ }^{2}$ Though several prominent environmental

\footnotetext{
2 To a much smaller extent-prior to the COVID-19 pandemic- the wildlife trade was targeted by several projects seeking to monitor pathogens in animal commodity chains as part of a larger concern surrounding zoonotic diseases since the 1990s (e.g., the Frenchfunded ZooCov and the longstanding monitoring of both humans and animals for Nipah virus in Thailand).
} 
organizations have championed or nominally adopted One Health approaches over the past two decades (Gruetzmacher et al. 2021), concerns around viral spillover from wild animal populations and broader connections between environmental and human health have, until recently, been similarly marginal to public outreach and communications strategy, policy design and practice.

Throughout 2020-2021, the problem of zoonoses and issues of global public health have become a pervasive feature of communication to publics and proposed policy as a "third pillar" of challenges facing the conservation movement, alongside biodiversity loss and climate change. These transformations have been prompted by the global impact of the COVID-19 pandemic beginning in early 2020 and, in particular, the proposed origin of the SARS-Cov-2 virus in illegally traded wildlife. By April of 2020, key international environmental organizations had issued formal statements or press releases that explicitly adopted a position on the emergence of COVID-19, all of which linked human health to environmental health and argued for enhanced conservation measures (Electronic Supplementary Material 1). In May of 2020, a group of scholars and conservation practitioners published an editorial essay in the IUCN-run journal PARKS that outlined the emerging impact of the pandemic on protected areas in terms of enforcement and encroachment, and articulated the need for a "new and transformative relationship with nature" as a means to prevent future viral spillover (Hockings et al. 2020 , p. 14). In pragmatic terms, the authors suggested the need to adopt a One Health approach within future conservation practice, and within this larger approach, highlighted the specific need to establish "a global One Health system of wildlife monitoring and surveillance that includes population status, interactions with humans, and potential for identifying infectious diseases as they emerge and before they become costly global pandemics" (McNeely 2021). By mid-2020, many large organizations had released significant reports that expanded on the earlier initial policy statements or briefs.

These reports provided more comprehensive overarching responses to the pandemic crisis, and in many cases provided specific policies. Many of the initial statements and reports that were released over the course of 2020 were collated into the "Wildlife Conservation 20 Declaration" released on the 20 November 2020, ahead of the online G20 summit. This declaration from prominent global wildlife conservation groups mapped out an expansive vision for preventing future pandemics that linked human and environmental health.

Surveying the policy framing and transformed agendas of major international and regional conservation groups, these responses fall into three broad categories (Fig. 1). The responses were not mutually exclusive, and often overlapped. The first response emphasizes the role of the illegal wildlife trade and other forms of wildlife exploitation (e.g., "bushmeat" consumption) in the creation of conditions conducive to viral spillover. Unsurprisingly, this is a response generated by groups that are focused on the elimination of the illegal wildlife trade in general (e.g., TRAFFIC) or organizations that are dedicated to the preservation of a particular animal or group of animals at risk from illegal trading (e.g., African Wildlife Foundation). At the same time, these groups often explicitly emphasized that the blame for emerging zoonoses should not be placed simply on the existence of wildlife or human proximity to wildlife, in order to not stigmatize particular species known to be viral reservoirs.

The second response located the emergence of COVID19 in humanity's dysfunctional relationship with the nonhuman world in a larger sense, pointing not only to the illegal wildlife trade or wildlife exploitation but other forms of environmental destruction that generate closer and potentially riskier human-wildlife interaction. This includes development in tropical forests (logging, agricultural expansion and intensification, resource extraction), changing demography at forest- interfaces and accelerating industrial animal production. Conservation International's Chief Executive Officer emphasized, for example, that while the pandemic offers a unique opportunity to end the illegal wildlife trade, which is a key site of viral spillover, "the real driver behind disease is deforestation". Or, as a report released by the World Wide Fund for Nature in June (2020) explained, zoonotic disease emergence is driven by "humanity's broken relationship with nature". The solution, in this framing, was to emphasize the need to reconfigure broader human-environmental interaction. This transformative vision was often translated into: (a) the need to better support existing conservation mechanisms, such as protected areas or environmental regulations; and (b) adopt new ways of doing conservation that acknowledge links between environmental and human health.

The third response points not only to the origins of COVID-19 in wildlife, but to the disruptive impact of the pandemic on enforcement and rehabilitation activities, diminished philanthropic funding and tourism revenue and increased poverty leading to greater environmental exploitation (e.g., more engagement in the illegal wildlife trade or illegal logging) (Lindsey et al. 2020; Smith et al. 2021).

\section{IMPLICATIONS IN THE CONTEXT OF CONTEMPORARY CONSERVATION DEBATES}

Conservation efforts have complex human impacts, particularly in developing nations with large, resource-dependent rural populations and rapidly developing forestfarm frontiers-precisely the areas identified as potential 


\section{Summary of conservation narratives responding to COVID-19}

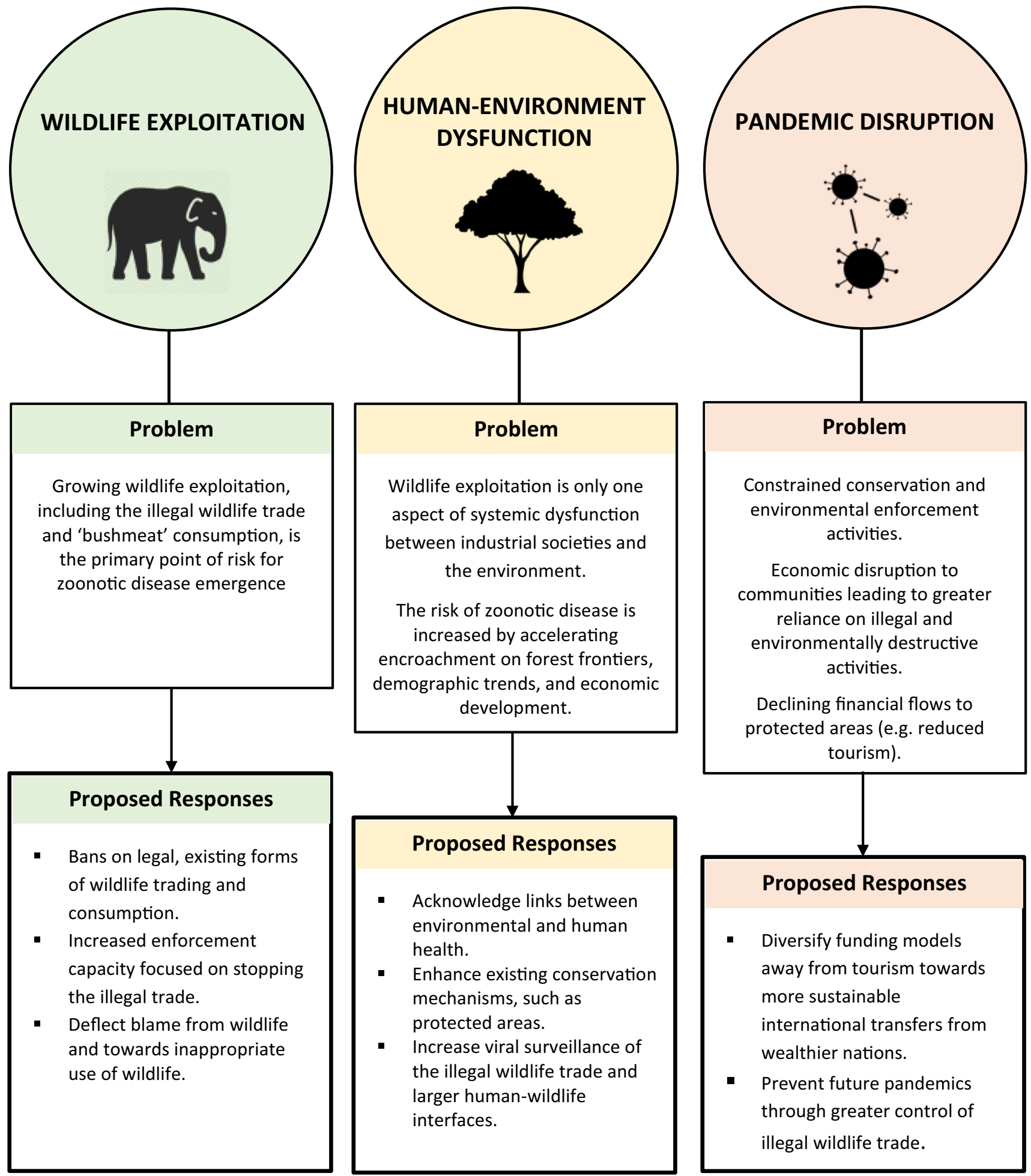

Fig. 1 Summary of conservation responses to COVID-19

"hotspots" for zoonotic disease emergence (Dobson et al. 2020). There is a significant body of literature focused on the social impacts of protected areas, but evidence broadly suggests that there are highly "contrary" impacts for human livelihoods near or within protected areas (West and Brockington 2006; Agrawal and Redford 2009; Holmes 
and Cavanagh 2016). The denial of access to resources or displacement may deepen poverty, for example, but support schemes may generate new sources of cash income (Brockington and Wilkie 2015). Beyond issues of access, many conservation projects, especially those branded as a community-based, require the intensive transformation of community values and aspirations to produce desirable environmental behavior in the form of new livelihood activities (Dressler 2014; Bluwstein 2017). Making matters even more complex, even when there are no direct measures to transform attitudes or deny access, many communities will also strategically conform to global or national expectations in order to maintain access to the support of civil society or international conservation groups (Brosius et al. 1998). Putting aside the still-unresolved debates that weigh costs and benefits across human and environmental outcomes of these various approaches, this social science scholarship has convincingly demonstrated that conservation schemes can have, for better or worse, profound impacts on where people live, how they sustain their households and how they relate to the nonhuman world.

Given these far-reaching impacts, any tentative shifts in the rationale and logic of global conservation objectives has direct implications for human lives and livelihoods and, therefore, should warrant close consideration for potential effects on policy and practice. The recent foregrounding of global public health as a foundational justification for environmental protection entails a potentially significant transformation in how and why biodiversity conservation should be achieved. A comparable example is the integration of climate change as a key objective of the environmental movement. Climate change has provided not only a compelling justification for habitat protection but spawned a global governance agenda that directly links financial markets in developed nations to the local livelihood practices of the rural poor throughout the world, for example, through the United Nations' controversial but wide-reaching Reducing Emissions from Deforestation and Forest Degradation or REDD + program (Milne et al. 2019). In light of the growing conversations between conservation groups and key development funders to design a new international environmental protection regime, ${ }^{3}$ there is a need to carefully evaluate what these changes will be and how they might impact existing conservation efforts. In the context of longstanding and well understand human impacts and social challenges surrounding environmental protection, I suggest there are two threads of concern.

\footnotetext{
${ }^{3}$ For example, the 'One Planet, One Health, One Future' conference held in 2020 was organized jointly by the Wildlife Conservation Society and Federal Foreign Office of the German government.
}

\section{Amplifying existing conservation tensions}

The perceived urgent need to prevent future pandemics derived from zoonotic diseases has been used to support calls for greater environmental protection and, specifically, the pandemic has been used by scholars and conservationists to support the call for a rapid increase in the scope and size of protected areas (Hockings et al. 2020; McNeely 2021). However, the urgency of these concerns risks amplifying existing tensions in conservation practice surrounding the impact of protected areas and other environmental protection tools. These concerns have already been noted in various ways by others (Dobson et al. 2020; Roe et al. 2020; Cawthorn et al. 2021; Walters et al. 2021), but they warrant briefly summarizing: the vast economic and social costs associated with pandemics and the emerging responses by state resource managements suggest there is a risk that efforts to prevent zoonotic disease emergence will provide a compelling and widely accepted justification for harsher environmental policies. Concern over infectious diseases may support arguments for neo-protectionist forms of conservation that can maintain strict boundaries between humans and the environment. That is, policy makers and publics globally may be willing to tolerate harm to people or animals in order to prevent the emergence of zoonotic diseases.

These concerns are particularly pronounced in terms of wildlife conservation. The link between COVID-19 and animal viral reservoirs has already prompted culling of animals deemed to pose a threat to humans and, historically, the framing of certain species as sites of viral spillover have resulted in spontaneous and sometimes illegal mass culling events (López-Baucells et al. 2018). In some areas, threat of a potential spillover event from wildlife, hunted for example for subsistence purposes, may be used as further justification for the removal of rural populations from ancestral territories or to bolster limitations on local wildlife use, as occurred during Ebola outbreaks across West Africa (Bonwitt et al. 2018).

Similarly, calls by scholars and conservation practitioners to enforce a blanket ban on wildlife consumption, with little differentiation between the rural poor and elite urban consumers (Yang et al. 2020), risks severely impacting communities that rely on the consumption of animals for food security (Roe et al. 2020). Community-based approaches to combatting the trade have only recently gained traction, which remains dominated by militarized responses that foster violence, meaning that gains for less punitive approaches are fragile (Cooney et al. 2017). While there has been some emphasis on the need to protect indigenous and local livelihoods in conservation responses to COVID-19 (Dobson et al. 2020), tentative state responses to the pandemic bear out the risk of punitive approaches becoming 
more prevalent. The proposed link between the illegal wildlife trade and zoonotic diseases has prompted quick and expansive responses from many governments, particularly in China and the Southeast Asian region, resulting in focused police attention on the trade, wildlife importation bans and punitive responses to wildlife exploitation. In the Philippines, for example, the Department of Environment and Natural Resources quickly banned the transportation of all non-timber forest products (a key source of livelihood support for indigenous and rural communities) as a precautionary measure (DENR 2020) and concern surrounding future pandemics has led to pending legislation entailing greatly expanded prison terms (up to 20 years) for harming endangered wildlife (Mercado 2020).

\section{New goals and unpredictable outcomes}

In addition to amplifying existing arguments for strict conservation regimes that exclude humans and more militarized solutions to wildlife exploitation, there are growing calls to incorporate One Health and biosecurity tools as routine features of conservation practice. While One Health and related approaches constitute a fairly expansive vision for pandemic prevention (Gruetzmacher et al. 2021), these proposals have centrally called for the development of biosurveillance in the form of "integrated monitoring systems for early detection of, and response to, emerging infectious diseases events" (Hockings et al. 2020, p. 18). This includes the expansion of passive event monitoring to include certain high-risk human communities and animal populations (i.e., at human-wildlife interfaces) who act as "sentinels" of potentially dangerous infectious diseases. Monitoring for clusters of symptoms might allow for quick identification of emerging infectious diseases and action that can prevent spread to more densely populated areas or spillover into domestic animal populations. Increasingly, however, biosurveillance projects employ anticipatory and routine sampling of human and animal populations for potentially dangerous pathogens. This involves widespread forms of molecular analysis of genetic samples from at-risk populations (e.g., close human residence to tropical forests or regular known interaction with wild animals known to be disease reservoirs). Genomic analysis has become a proven technology in mapping the spread and origins of recent viral outbreaks, particularly in the Ebola, Zika and COVID-19 outbreaks. Viral monitoring programs targeting various dimensions of the human-wildlife interface are not unprecedented, and there have been several significant projects of global viral surveillance, such as USAID's decade-long PREDICT program and the emerging Global Virome Project.

However, the integration of biosurveillance of humans and animals into conservation raises new and unpredictable points of tension in an already fraught space of negotiation between state environmental managers and rural communities living within or adjacent to protected areas. Virologists and others concerned with zoonotic diseases have long argued for a globalized system of early warning targeting vulnerable peoples "with high levels of exposure to wild animals, such as hunters, butchers of wild game, wildlife veterinarians, workers in the wildlife trade..." (Wolfe, Dunavan and Diamond 2007, p. 283; Keutsch et al. 2010; Gardy and Loman 2018). Scaling up these techniques into a system of continuous and global surveillance within protected areas, as now widely emphasized as a response to COVID-19 (Dobson et al. 2020), may prove particularly challenging given that: (a) the most at-risk communities are also those most likely to have experienced deprivation resulting from conservation practices or are reliant on criminalized livelihood activities; and (b) any such project is strongly dependent on local compliance and cooperation with those who are envisioned to be prospective partners in disease monitoring (Bird and Mazet 2018).

In light of historical conflicts around monitoring and surveillance in conservation, there are three key points of tension. First, there is already considerable distrust surrounding the surveillance of resource use by non-governmental and state actors, particularly in tropical forests identified as most at risk of spillover events. Even in settings where community-based conservation has become the norm, the illegal access and use of resources is frequently managed through punitive punishment. Monitoring resource access has taken the form of patrols by, for example, park rangers and project officers or in-community enforcement mechanisms. More recently, the growing use of low-cost drones, in addition to other increasingly affordable sensing technologies, has further fueled suspicions in many communities toward conservation efforts (Sandbrook 2015). Similarly, existing efforts to track and monitor wildlife for other reasons have been challenged by communities as invasive (Sandbrook et al. 2018; Sharma et al. 2020). Given that existing viral monitoring aims to elicit detailed information regarding rural households, their livelihood activities and potentially illegal use of wildlife (e.g., Smiley Evans et al., 2018), it is likely that biosurveillance would exacerbate any existing tensions around privacy and resource use.

Second, the medical sampling of humans, particularly indigenous peoples, but also many marginalized rural populations, has a long and fraught history and has produced, in many cases, high levels of distrust in public health institutions and agents (Kowal and Radin 2015). A lack of sewage systems to conduct community-level monitoring of viral presence in most remote areas means genetic material would need to be regularly collected from 
vulnerable populations living near high-risk areas at the individual level. Indeed, the existing literature that examines One Health approaches notes this as a potential source of concern, with scholars emphasizing that there are considerable ethical issues surrounding storage of human genetic material and the need for considerable trustbuilding at the local level (Lajaunie et al. 2014; Bird and Mazet 2018). In light of these existing concerns, it is likely that efforts to collect sensitive livelihood data, personal medical information and genetic material, in addition to greater scientific access and control of locally valued wildlife, will require careful negotiation.

Finally, in addition to issues confronting human sampling, there is a growing awareness in many forest communities that the collection of plant and animal material is closely connected to biopiracy (Mgbeoji 2014). Indeed, existing viral monitoring programs face considerable challenges surrounding issues of intellectual property and the potentially uneven distribution of benefits derived from identifying particularly dangerous zoonotic diseases. Geopolitical questions over who owns viruses and who can and should benefit from commercial vaccine development remain definitively unanswered by global regulatory frameworks (Porter 2019). Indigenous peoples therefore face the prospect of having what is now considered to be a significant biological resource (i.e., potentially dangerous pathogens) appropriated by a global public health regime that works to benefit, primarily, wealthy developed nations and their pharmaceutical industries (Richardson 2020).

The precise impacts of these programs are difficult to predict with certainty, most significantly because One Health and related approaches have not matured into a consistent model of governing human-environmental interactions. There is an emerging consideration of how social science approaches might aid One Health applications, but little exploration of the social, cultural and political challenges and impacts that arise from One Health projects, such the USAID PREDICT program. Nevertheless, the challenges of these transformations have not been unrecognized. Proposals to integrate One Health approaches or greatly expand protected area size have reiterated existing commitments to the rights of local resource users (Dobson et al. 2020; Hockings et al. 2020, p. 18; Walters et al. 2021). The WC20 Declaration (2020), for example, explicitly emphasizes that G20 states "need to respect the rights, and enhance the livelihoods and well-being of IPLCs [Indigenous Peoples and Local Communities] living within and/or depending on natural ecosystems" in the formulation and enactment of wildlife protection policy and programs. However, the statement presents a somewhat optimistic scenario in which targeted communities will easily or readily "define and participate in wildlife guardianship" or submit to forms of new and invasive biosurveillance. The recent history of conservation-and wildlife conservation in particular-suggests that local ideas of guardianship can differ, quite radically, from those envisioned by environmental groups. There is little recognition, perhaps to avoid risking stigmatizing already marginalized people, of the deep economic reliance of many potential "wildlife guardians" on the illegal wildlife trade (Smith 2020; Smith and Theriault 2020). Following existing community-based wildlife conservation programs, there is also little focus placed on unpicking these complex and ethically challenging dependencies beyond seeking to provide alternative livelihoods. Indeed, purported efforts to safeguard the rights of local peoples repeats older, and arguably ineffective, strategies with little consideration of the distinct and unpredictable effects of integrating biosecurity tools and strategies into conservation practice.

\section{CONCLUSION}

A powerful consensus among global conservation organizations and multilateral institutions has emerged in response to the ongoing COVID-19 pandemic. For the foreseeable future, it is likely that many environmental groups will continue to leverage perceived links between wildlife exploitation, and environmental destruction more generally, and zoonotic diseases in advocacy and policy design. What this might entail has yet to emerge in a concrete form, but both scholars and conservation practitioners have promoted both: (a) the extension of existing conservation mechanisms (e.g., greater or new sources of funding, more protected areas); and (b) the incorporation of biosecurity technologies and strategies into traditional biodiversity conservation. The potential impacts of the former are likely to be relatively straightforward. If the existing tensions surrounding people-park conflicts are not addressed, more protected areas may amplify social conflicts already in place. More protected areas could very conceivable lead to, for example, greater human displacement and the need to provide new and sustainable livelihoods to large groups of people. In the latter case, however, the introduction of novel technologies, goals and justifications for environmental protection makes the prediction of likely social impacts challenging, particularly given that the construction of a global system of zoonoses management is dependent on genetic screening or intensive symptom monitoring of both humans and animals. The history of conservation practice suggests that these are unlikely to be adopted readily and will require sustained information dissemination and education campaigns.

There are two key recommendations emerging from these insights. First, there is clearly a dearth of research surrounding the social conflict involved in issues of 
biosurveillance. Beyond a lack of data resulting from the relative novelty of viral monitoring on a large scale, this indicates a troubling belief that fairly invasive management tools can be readily inserted into an already conflict-ridden sector. Rigorous social research, attuned to historical and ongoing conflicts in conservation, as these projects unfold may help mitigate new tensions as or before they arise. Second, the little research that does exist surrounding One Health projects points to a need for a regulatory framework that addresses the ethical concerns surrounding the collection and storage of human and animal genetic material on a vast scale, as well as issues of privacy in the collection of medical and livelihood data. While in many developed nations genetic material is protected by fairly robust systems of regulation, this is not the case across the developing tropical world where biosurveillance will largely target vulnerable communities whose rights are still subverted and poorly upheld by legal systems. Varied national responses to biopiracy concerns suggest there is a global desire and capacity to protect the rights of forest-dwelling communities, for example, but relying on processes of country-level legislative responses has produced an uneven international regulatory landscape. The current and broad consensus by conservation groups and policy makers indicates there is a significant opportunity to address some of the biggest challenges surrounding these issues prior to their application.

Despite what this article has identified as a comprehensive change in public outreach and policy framing, the incorporation of biosecurity measures into biodiversity conservation remains speculative. Whether biosecurity concerns, and specifically One Health approaches and systems of biosurveillance, will emerge as a sustained and meaningful element of conservation practice as demanded in response to the COVID-19 pandemic remains an open question. However, given the sweeping changes these proposed strategies would entail, and their potential impacts, they warrant close examination.

Acknowledgements This research has been supported through a fellowship from the Alfred Deakin Institute.

\section{REFERENCES}

Agrawal, A., and K. Redford. 2009. Conservation and displacement. Conservation and Society 7: 1-10.

Bird, B.H., and J.A.K. Mazet. 2018. Detection of emerging zoonotic pathogens: An integrated one health approach. Annual Review of Animal Biosciences. https://doi.org/10.1146/annurev-animal030117-014628.

Bluwstein, J. 2017. Creating ecotourism territories: Environmentalities in Tanzania's community-based conservation. Geoforum. https://doi.org/10.1016/j.geoforum.2017.04.009.
Bonwitt, J., M. Dawson, M. Kandeh, R. Ansumana, F. Sahr, H. Brown, and A.H. Kelly. 2018. Unintended consequences of the 'bushmeat ban' in West Africa during the 2013-2016 Ebola virus disease epidemic. Social Science \& Medicine. https://doi. org/10.1016/j.socscimed.2017.12.028.

Brockington, D., and D. Wilkie. 2015. Protected areas and poverty. Philosophical Transactions of the Royal Society b: Biological Sciences. 370: 20140271.

Brosius, J.P., A.L. Tsing, and C. Zerner. 1998. Representing communities: Histories and politics of community-based natural resource management. Society and Natural Resources 11: $157-168$.

Cawthorn, D.-M., A. Kennaugh, and S.M. Ferreira. 2021. The future of sustainability in the context of COVID-19. Ambio 50: 812-821. https://doi.org/10.1007/s13280-020-01430-9.

Conservation International. 2020. Conservation International Statement in Support of Wildlife Conservation 20's Urgent Message to the G20: Invest in Nature or Face Growing Pandemic Risk. Retrieved February 15, 2021, from https://www.conservation. org/press-releases/2020/11/20/conservation-internationalstatement-in-support-of-wildlife-conservation-20's-urgentmessage-to-the-g20-invest-in-nature-or-face-growing-pandemicrisk.

Cooney, R., D. Roe, H. Dublin, J. Phelps, D. Wilkie, A. Keane, H. Travers, D. Skinner, et al. 2017. From poachers to protectors: Engaging local communities in solutions to illegal wildlife trade. Conservation Letters 10: 367-374.

DENR. 2020. DENR suspends forest products, wildlife transport. Biodivers. Manag. Bur. Retrieved June 3, 2020, from https:// bmb.gov.ph/index.php/resources/news-and-events/99-denrsuspends-forest-products-wildlife-transport.

Dobson, A.P., S.L. Pimm, L. Hannah, L. Kaufman, J.A. Ahumada, A.W. Ando, A. Bernstein, J. Busch, et al. 2020. Ecology and economics for pandemic prevention. Science 369: 379.

Dressler, W. 2014. Green governmentality and swidden decline on Palawan Island. Transactions of the Institute of British Geographers 39: 250-264.

Gardy, J.L., and N.J. Loman. 2018. Towards a genomics-informed, real-time, global pathogen surveillance system. Nature Reviews Genetics 19: 9.

Gruetzmacher, K., W.B. Karesh, J.H. Amuasi, A. Arshad, A. Farlow, S. Gabrysch, J. Jetzkowitz, S. Lieberman, et al. 2021. The Berlin principles on one health-Bridging global health and conservation. Science of the Total Environment. https://doi.org/10.1016/j. scitotenv.2020.142919.

Hinchliffe, S. 2015. More than one world, more than one health: Reconfiguring interspecies health. Social Science \& Medicine 129: $28-35$.

Hockings, M., N. Dudley, W. Elliott, M.N. Ferreira, K. Mackinnon, M.K. Pasha, A. Phillips, S. Stolton, et al. 2020. Editorial essay: Covid-19 and protected and conserved areas. Parks 26: 7-24.

Holmes, G., and C.J. Cavanagh. 2016. A review of the social impacts of neoliberal conservation: Formations, inequalities, contestations. Geoforum. https://doi.org/10.1016/j.geoforum.2016.07. 014.

Keutsch G., M. Pappaioanou, M. Gonzalez, K. Scott, and P. Tsai. 2009. Sustaining global surveillance and response to emerging zoonotic diseases. Institute of Medicine and National Research Council: Washington, DC.

Kowal, E., and J. Radin. 2015. Indigenous biospecimen collections and the cryopolitics of frozen life. Journal of Sociology 51: 63-80.

Lajaunie, C., S. Morand, and T.B. Huan. 2014. Barcoding, biobanking, ebanking for "One Health" projects in South-East Asia: considering ethics and international law. Eubios Journal of Asian and International Bioethics 24: 129-131. 
Lindsey, P., J. Allan, P. Brehony, A. Dickman, A. Robson, C. Begg, H. Bhammar, L. Blanken, et al. 2020. Conserving Africa's wildlife and wildlands through the COVID-19 crisis and beyond. Nature Ecology and Evolution 4: 1300-1310.

López-Baucells, A., R. Rocha, and Á. Fernández-Llamazares. 2018. When bats go viral: Negative framings in virological research imperil bat conservation. Mammal Review 48: 62-66.

McElwee, P., E. Turnout, M. Chiroleu-Assouline, J. Clapp, C. Isenhour, T. Jackson, E. Kelemen, D.C. Miller, et al. 2020. Ensuring a post-COVID economic agenda tackles global biodiversity loss. One Earth 3: 448-461.

McNeely, J.A. 2021. Nature and COVID-19: The pandemic, the environment, and the way ahead. Ambio. 50: 767-781. https:// doi.org/10.1007/s13280-020-01447-0.

Mercado, N.A. 2020. House panel OKs bill seeking heavier penalties for wildlife abuse. INQUIRER.net. Retrieved from March 3, 2021, from https://newsinfo.inquirer.net/1367144/house-paneloks-bill-seeking-heavier-penalties-for-wildlife-abuse.

Mgbeoji, I. 2014. Global biopiracy: Patents, plants, and indigenous knowledge. Vancouver: UBC Press.

Milne, S., S. Mahanty, P. To, W. Dressler, P. Kanowski, and M. Thavat. 2019. Learning from 'actually existing' REDD+. Conservation and Society 17: 84-95.

Porter, N. 2019. Viral economies: Bird flu experiments in Vietnam. Chicago: University of Chicago Press.

Richardson, E.T. 2020. Epidemic illusions: On the coloniality of global public health. New York: MIT Press.

Roe, D., A. Dickman, R. Kock, E.J. Milner-Gulland, E. Rihoy, and M. 'tSas-Rolfes. 2020. Beyond banning wildlife trade: COVID-19, conservation and development. World Development. https://doi. org/10.1016/j.worlddev.2020.105121.

Sandbrook, C. 2015. The social implications of using drones for biodiversity conservation. Ambio 44: 636-647. https://doi.org/ 10.1007/s13280-015-0714-0.

Sandbrook, C., R. Luque-Lora, and W.M. Adams. 2018. Human bycatch. Conservation and Society 16: 493-504.

Schmeller, D.S., F. Courchamp, and G. Killeen. 2020. Biodiversity loss, emerging pathogens and human health risks. Biodiversity and Conservation 29: 3095-3102.

Sharma, K., M. Fiechter, T. George, J. Young, J.S. Alexander, A. Bijoor, K. Suryawanshi, C. Mishra, et al. 2020. Conservation and people: Towards an ethical code of conduct for the use of camera traps in wildlife research. Ecological Solutions and Evidence 1: e12033.

Smiley Evans, T., L. Tutaryebwa, K.V. Gilardi, P.A. Barry, A. Marzi, M. Eberhardt, B. Ssebide, M.R. Cranfield, et al. 2018. Suspected exposure to filoviruses among people contacting wildlife in
Southwestern Uganda. Journal of Infectious Diseases 218: S277-S286.

Smith, W. 2020. Beyond loving nature: Affective conservation and human-pig violence in the philippines. Ethnos. https://doi.org/10. 1080/00141844.2020.1828970.

Smith, M.K., I.P. Smit, L.K. Swemmer, M.M. Mokhatla, S. Freitag, D.J. Roux, and L. Dziba. 2021. Sustainability of protected areas: Vulnerabilities and opportunities as revealed by COVID-19 in a national park management agency. Biological Conservation. https://doi.org/10.1016/j.biocon.2021.108985.

Smith, W., and N. Theriault. 2020. Seeing Indigenous Land Struggles in the "Multispecies Cloud" of Covid-19. Soc. Cult. Anthropol. Retrieved July 29, 2020, from https://culanth.org/fieldsights/ seeing-indigenous-land-struggles-in-the-multispecies-cloud-ofcovid-19?x-craft-preview=yZzQrZbTLC\&token=N6TA2zZy9YD vpCRA2wqczJGfOnzAHIOb.

Walters, G., N. Broome, M. Cracco, T. Dash, N. Dudley, S. Elías, O. Hymas, S. Mangubhai, et al. 2021. COVID-19, indigenous peoples, local communities and natural resource governance. PARKS. 27: 57-62.

West, P., and D. Brockington. 2006. An anthropological perspective on some unexpected consequences of protected areas. Conservation Biology 20: 609-616.

Wolfe, N.D., C.P. Dunavan, and J. Diamond. 2007. Origins of major human infectious diseases. Nature 447: 279-283.

$\mathrm{Wu}, \mathrm{T} .2021$. The socioeconomic and environmental drivers of the COVID-19 pandemic: A review. Ambio 50: 822-833. https://doi. org/10.1007/s13280-020-01497-4.

Yang, N., P. Liu, W. Li, and L. Zhang. 2020. Permanently ban wildlife consumption (ed J. Sills). Science 367: 1434.

Publisher's Note Springer Nature remains neutral with regard to jurisdictional claims in published maps and institutional affiliations.

\section{AUTHOR BIOGRAPHY}

Will Smith $(\square)$ is an Associate Research Fellow at the Alfred Deakin Institute, Deakin University. He is an environmental anthropologist and human geography whose research interests include human-forest interfaces, the social dimensions of agricultural production, and the politics of indigenous knowledge in both Australia and upland Southeast Asia.

Address: Alfred Deakin Institute, Deakin University, Building C, Level 1, Burwood, Victoria 3125, Australia.

e-mail: will.smith@deakin.edu.au 